\title{
Response of Leaf Biomass, Leaf and Soil C:N:P Stoichiometry Characteristics to Different Site Conditions and Forest Age: A Case of Pinus Tabuliformis Plantations in the Temperate Mountainous Area of China
}

Ping Liu

Shenyang Agricultural University

Lijiao Wang

Shenyang Agricultural University

Xin Jing

Shenyang Agricultural University

Lei Yu

Shenyang Agricultural University

Yutao Wang ( $\nabla$ ytw730@syau.edu.cn )

Shenyang Agricultural University

\section{Research}

Keywords: Pinus tabuliformis plantation, over the entire life cycle, ecological stoichiometric characteristics, leaf biomass

Posted Date: May 27th, 2021

DOI: https://doi.org/10.21203/rs.3.rs-527333/v1

License: (1) This work is licensed under a Creative Commons Attribution 4.0 International License. Read Full License 


\section{Abstract}

Background: Ecological stoichiometry is an important index that reflects the element cycle and ecosystem stability. In this study, two sites (sunny and shady slopes) and five forest ages (young forest, middle-aged forest, near-mature forest, mature forest, and over-mature forest) in a Pinus tabuliformis plantation were chosen to illustrate the effects of forest age and site on the biomass and stoichiometric characteristics of leaves and soils in the temperate mountainous area of China.

Results: For all forest ages, the biomass, leaf total carbon, leaf total nitrogen, leaf total phosphorus of the leaves of $P$. tabuliformis on sunny slopes were all higher than those on shady slopes, while the nitrogen and phosphorus contents of the leaves showed the opposite of this. The biomass of leaves increased on sunny slopes, and increased first and then decreased in shady slopes with increasing forest age. The contents of soil total carbon (STC) and soil total nitrogen (STN) decreased with increasing soil depth, while the soil total phosphorus (STP) and soil available phosphorus (SAP) contents displayed the opposite. In addition to SAP, the average content of STC, STN, and STP in shady slopes was higher than that in sunny slopes, and the ratio was the opposite. Except for STC:STN on shady slopes, the other ratios showed a downward trend with an increase in soil depth. Excluding the topsoil, the change trend of STC:STP and STN:STP in shady slopes and sunny slopes was consistent with forest age.

Conclusions: The results showed that forest age and site conditions had significant effects on leaf biomass. The biomass of the leaves is mainly limited by nitrogen. In management, it is recommended to plant on sunny slopes, especially in the young stage of $P$. tabuliformis plantation. In addition, it is suggested to apply a reasonable amount of nitrogen fertilizer to increase leaf biomass.

\section{Background}

Forest ecosystems are the main constitute of terrestrial ecosystems (Bing et al. 2008), which play a pivotal role in coping with global climate change, maintaining ecological balance, and protecting biodiversity. In complex forest ecosystems, plants, soil, and litter are the most important components of the ecosystems. Soil is the basis for plant survival. It provides nutrients and water for plants, and plants return nutrients to the soil through dead branches and leaves. These three factors are closely linked and there is an extremely close relationship between plant and soil C, N, and P stoichiometric characteristics. Based on the principles and methods of ecological stoichiometry, it is of great significance to study the ecological stoichiometry characteristics of total carbon, total nitrogen, and total phosphorus of plants and soils in forest ecosystems to reveal the nutrient limitation and the mechanism of element cycling and balance. Ecological stoichiometry is the application of stoichiometry in ecology. It is a new subject developed in the last 20 years and a new method to study plant-soil interactions and the carbon, nitrogen, and phosphorus cycle (Lin, Y 2020), which provides a good index and research direction for the study of plant-environment interactions (Bowen et al. 2020). In ecological stoichiometry, each element has a different role, among which carbon plays the part of a structural element in the plant body, and nitrogen and phosphorus play an important role in determining the limiting factors of plant

productivity (Zhang et al. 2004, Wassen et al. 1995). Studies have found significant differences in nitrogen and phosphorus contents between plant phylogenetic stages (coniferous and broad-leaved) and plant functional groups (tree, shrub, and grass), and the seasonal variation has been found to be strongly reflected in the leaves 
(Jingming et al. 2021). The C:N and C:P ratios among the three can represent the nitrogen and phosphorus nutrient utilization efficiency and carbon assimilation capacity of plants, and the N:P ratio can reflect the characteristics of the supply and limitation of nitrogen and phosphorus nutrients to plants in the ecosystem (Yang et al. 2020). Soil is the main site of biogeochemical cycles in terrestrial ecosystems. Changes and the distribution of soil nutrients directly affect the availability of plant nutrients (Junhua et al. 2020). Plant biomass is an important indicator of plant growth (Huang et al. 2020). The stability of plant elements in different growth and development stages, along with the relationship between plant growth biomass allocation and the content and ratio of nitrogen and phosphorus elements have become the focus of ecological stoichiometry research (Wang et al. 2008, Wu et al. 2010 ). To date, many studies on modeling individual tree biomass in China have been published (Zou et al. 2015). Stands of different ages require different allometric biomass equations (Mensah et al. 2016). Because of the differences in studies (Yang et al. 2019, Wang et al. 2013, Lie et al. 2016), there are significant differences in tree biomass among different age groups, leaving some researchers believe that plants with stable stoichiometric characteristics have higher and more stable biomass (Güsewell 2009). Biomass is the material and energy basis of the entire forest ecosystem and is the basis for studying the productivity, net primary productivity, and carbon cycle in a forest. Metrological characteristics can intuitively reflect plant nutrient content and nutrient utilization strategies (Ting et al. 2015). The distribution pattern and changes in the nutrient content of the soil will greatly affect the growth and development of plants in the forest stand (Xingzhao et al. 2010). Therefore, understanding the terrestrial ecosystem which includes plant leaves and soil carbon, nitrogen, and phosphorus nutrient elements and their relationship with biomass, along with exploring the sources of plant nutrients in the soil nutrient cycling and balance constraint relationship between them, has important significance in improving the refinement of local forestry management.

At present, ecological stoichiometry has made great progress worldwide, especially in the study of forest and aquatic ecosystems. Compared with Western countries, China's relevant research theory has had a late start, and there is still a big gap within the knowledge. Since Elser et al. (1996) first clearly put forward the concept of ecological stoichiometry, an increasing number of ecologists have begun to pay attention to and devote themselves to this field (Elser et al. 2000, Tessier et al. 2003, Giisewell et al. 2004, Elser et al. 2010, Sistla et al. 2012). The related research mainly focuses on the following aspects: the ecological stoichiometry characteristics of plant leaves in forest and grassland ecosystems, the changes in different climate environments, and the determination of plant body restrictive factors under different environmental conditions. Usuda et al. (1995) found that with the growth of plants, the concentration of nitrogen in plant leaves gradually decreased, and the N:P ratio of mature plants was higher than that of young plants. Kerkhoff et al. (2006) found significant differences in the stoichiometric characteristics among different organs of the same plant. Through data collection and sorting, Ren Shujie et al. (2007) analyzed the stoichiometric characteristics of more than 650 species of plants from 168 samples in the north-south transect in eastern China. Chinese vegetation was found to be susceptible to phosphorus limitation. Ding Fan et al. (2011) found that the nitrogen content in the leaves of the three main plants in the Songnen Plain had great differences, while the phosphorus content showed no significant differences. The N:P ratio in plant leaves was greatly affected by the content of soil nutrients, such as carbon, nitrogen, and phosphorus. Studies have shown that leaf nitrogen and phosphorus content can affect the final allocation of plant biomass. For example, high nitrogen can increase the proportion of aboveground plant parts (Andrews et al. 2006, Fan et al. 2008). Yaonian and Mingxi (2015) believe that the physical and chemical properties of soil will, to a certain extent, play a decisive role in the spatial distribution of aboveground biomass in forests. However, there are few studies on the effects of soil 
carbon, nitrogen, and phosphorus on leaf biomass and carbon, nitrogen, and phosphorus contents in leaves and soil, especially under different forest ages and site conditions.

Pinus tabuliformis is an important tree species for afforestation and soil and water conservation in the temperate mountainous area of China, and a large area of $P$. tabuliformis plantations has been formed, which plays a very important ecological role in the environment of the area. Therefore, this study used $P$. tabuliformis plantations in Fushun County as the research object. The leaf biomass, total carbon (LTC), total nitrogen (LTN), total phosphorus (LTP), soil total carbon (STC), total nitrogen (STN), total phosphorus (STP), and available phosphorus (SAP) in P. tabuliformis plantations over the entire life cycle were determined. The purpose of this study was to test the following three hypotheses: 1) It is assumed that the biomass and element content of leaves in $P$. tabuliformis plantations are related to forest age and site, and the biomass and element content of leaves in different growth stages will change with the different needs of plants, 2) it is assumed that soil $\mathrm{C}: \mathrm{N}$ : $\mathrm{P}$ stoichiometry will have a certain effect on leaf biomass, and 3) in the long run, soil C:N:P stoichiometry will significantly affect leaf C:N:P stoichiometry.

\section{Methods}

\section{Study Site and Experimental Design}

The mountainous area of eastern Liaoning Province, China, has a temperate monsoon climate zone, with a long cold winter and short rainy summer. The average annual precipitation is $700-850 \mathrm{~mm}$, average annual evaporation is $925-1284 \mathrm{~mm}$, average annual temperature is $4-11^{\circ} \mathrm{C}$, and the frost-free period is $120-139$ days. This region belongs to the extension area of the Changbai Mountains, with an average altitude of 200$500 \mathrm{~m}$ and a few peaks exceeding $1000 \mathrm{~m}$. The soil is dominated by dark brown loam, generally acidic or neutral loam. In the present study, P. tabuliformis plantation sample plots with similar density, different slope directions, and different forest ages were established in the Magu Forest Farm of Fushun County, Liaoning Province. The plots in each slope direction included five age classes: young forest (YF), middle-aged forest (MAF), near-mature forest (NMF), mature forest (MF), and over-mature forest (OMF). Each age level had three sample plots for a total of 30 permanent sample plots. The area of each sample plot was $0.06 \mathrm{hm}^{2}(20 \mathrm{~m} \times$ 30). Two trees representing the average tree height and diameter at breast height (DBH) in each sample plot were selected as standard trees. The $\mathrm{DBH}$, tree height, height under the branch of $P$. tabuliformis, stand density, forest age, and other stand indices were measured using a DBH ruler, tape, and altimeter. The basic data of the samples are listed in Table 1.

\section{Leaf Samples}

Leaf samples were collected in 2019. The standard wood canopy was divided into three layers: upper, middle, and lower. Two standard branches were selected from each layer for a total of six standard branches. Each standard branch intercepted one sample leaf, which was saved in a numbered envelope. A total of 360 leaf samples were collected from 60 standard trees. The collected leaf samples were weighed, and the fresh weights were recorded. The leaves were cured at $105^{\circ} \mathrm{C}$ for $30 \mathrm{~min}$ and then dried at $65^{\circ} \mathrm{C}$ to a constant weight. The leaf samples were weighed, and the dry weights were recorded. The biomass of the leaves was then calculated. 


\section{Determination of Biomass of Leaf per Plant}

To reduce the error caused by the water loss of needles in the process of removing needles from the standard branches, the fresh weight of the cut standard branches with leaves in each layer was weighed and recorded as $M_{1}$, and the fresh weight of needles was recorded as $M_{2}$ after removing the weighing branches, and the fresh weight of needles was recorded as $M_{1}-M_{2}$. After weighing the fresh weight of the sampling branches and sample leaves, they were placed in a laboratory oven and baked to a constant weight at a constant temperature of $80^{\circ} \mathrm{C}$. Then, the biomass calculation formula for each layer of leaves is as follows:

$W=\left(M_{1}-M_{2}\right) \times N \times P$

where $W$ is leaf biomass, $M_{1}$ is the standard branch weight with leaves, $M_{2}$ is the standard branch weight, $N$ is the number of standard branches, and $\mathrm{P}$ is the leaf water content (dry weight of sample leaves versus fresh weight of sample leaves).

The obtained leaf biomass of each layer was added as the biomass of leaf per plant.

\section{Soil Samples}

Soil samples were collected in 2019. The underground part of the standard wood was sampled from the soil profile using the soil drilling method. A cross section of $1 \mathrm{~m} \times 0.5 \mathrm{~m} \times 0.6 \mathrm{~m}$ in length $\times$ width $\times$ depth was dug at the base of each standard wood, and samples were taken from three soil layers at different depths $(0-20$, $20-40$, and $40-60 \mathrm{~cm}$ ), $0.5 \mathrm{~m}$ and $1 \mathrm{~m}$ from the base of the trunk. The soil samples that had rocks and debris removed were transported to the laboratory and air-dried. In total, 360 soil samples were collected.

\section{Elements in Leaf and Soil Samples}

Before determining the element content, the samples of leaves and soils (different distances, same soil layer) from the same area were mixed to form composite samples. The composite samples of leaves were ground and screened with a 60-mesh sieve, whereas the soil composite samples were air-dried and screened with a 100-mesh sieve. All samples were then placed into self-sealing bags, numbered, sealed, and stored until subsequent determination. The total carbon and nitrogen contents of the leaf and soil samples were determined using an elemental analyzer (Vario EL III, Elementa Langensel bold, Germany). The total phosphorus content of leaves was determined using the molybdenum blue colorimetric-spectrophotometer method, while the total phosphorus content of the soil was determined using the $\mathrm{HCLO}_{4}-\mathrm{H}_{2} \mathrm{SO}_{4}$-molybdenumantimony colorimetric method. The available phosphorus in the soil was determined with $0.5 \mathrm{~mol} / \mathrm{L} \mathrm{NaHCO}{ }_{3}$ leaching and the molybdenum-antimony colorimetric method.

\section{Statistical Analysis}

Data processing was performed using SPSS 22.0. The differences in the biomass, total carbon, total nitrogen, and total phosphorus content in leaf and soil ecological stoichiometry and its ratio throughout the entire life cycle at different sites were examined using single factor variance analysis. Duncan's multiple comparison method was used for significance analysis $(a=0.05)$. Furthermore, the ecological stoichiometry and ratio of soil and its correlation with leaf biomass was also analyzed by Person correlation analysis. The same 
correlation analysis was used to examine the ecological stoichiometry and ratio of soil and its correlation with leaf biomass. The relationships between the ecological stoichiometry and the ratio of the surface soil (0-20 $\mathrm{cm})$, the ecological stoichiometry and ratio of leaves, along with the ecological stoichiometry and ratio of soil and its correlation with leaf biomass in P. tabuliformis plantations were analyzed by Pearson correlation analysis.

\section{Results}

\section{Leaf Biomass Per Plant in Pinus Tabuliformis Plantation}

Over the entire life cycle of the $P$. tabuliformis plantation, the average biomass of leaves was $38.86 \mathrm{~kg}$ on sunny slopes and $22.43 \mathrm{~kg}$ on shady slopes.

The leaf biomass of the sunny slope gradually increased with increasing forest age and reached a maximum in the OMF (Fig. 1). The leaf biomass of YF was significantly different from that of the other forest ages. The leaf biomass of the shady slope first increased and then decreased with the increase in forest age and reached the maximum value in NMF. At the same forest age, the biomass of leaves at different sites was significantly different only in MAF and OMF. The results showed that the biomass of leaves on the sunny slope was higher than that on the shady slope and increased with increasing forest age. However, the leaf biomass in shady slopes first increased and then decreased with increasing forest age.

\section{Leaf Ecological Stoichiometric Characteristics}

\section{LTC, LTN, and LTP Content}

Over the entire life cycle of the $P$. tabuliformis plantation, the average carbon content in the leaves was 480.89 $\mathrm{g} \cdot \mathrm{kg}^{-1}$ on sunny slopes and $465.86 \mathrm{~g} \mathrm{~kg}^{-1}$ on shady slopes (Fig. $2 \mathrm{~A}$ ), the average nitrogen content in the leaves was $14.39 \mathrm{~g} \mathrm{~kg}^{-1}$ on sunny slopes and $15.25 \mathrm{~g} \mathrm{~kg}^{-1}$ on shady slopes (Fig. 2B), and the average phosphorus content in the leaves was $1.78 \mathrm{~g} \cdot \mathrm{kg}^{-1}$ on sunny slopes and $2.01 \mathrm{~g} \cdot \mathrm{kg}^{-1}$ on shady slopes (Fig. 2C).

In the same site type, there was no significant difference in the contents of carbon, nitrogen, and phosphorus in the leaves of sunny slopes among different ages. The carbon content of leaves in shady slopes was significantly different between the other forest ages, excluding NMF and OMF. Except for YF and OMF, there was a significant difference in the nitrogen content of leaves between the other forest ages. There was no significant difference in the phosphorus content of leaves among the different forest ages. In the same forest age, the carbon content of leaves in MAF and NMF was significantly different between the two site types. The nitrogen content of leaves in YF, MAF, and MF was significantly different between the two site types while the phosphorus content of leaves in NMF was significantly different between the two site types.

The results showed that the contents of carbon, nitrogen, and phosphorus in leaves did not change significantly with forest age. The average nitrogen and phosphorus contents of leaves on shady slopes were higher than those on sunny slopes, but the law of carbon content of leaves was the opposite.

\section{Stoichiometric Ratio of LTC, LTN, and LTP}


Over the entire life cycle of the $P$. tabuliformis plantation, the average LTC:LTN ratio was 33.71 in the sunny slope and 30.92 in the shady slope (Fig. 3A), the average LTC:LTP ratio was 274.43 , in the sunny slope and 235.17, in the shady slope (Fig. 3B), and the average LTN:LTP ratio was 8.21, in sunny slopes and 7.67, in shady slopes (Fig. $3 \mathrm{C}$ ). The results showed that LTC:LTN had no obvious change with forest age. LTC:LTP and LTN:LTP both reached their maximum values at MF or OMF. The LTC:LTN, LTC:LTP, and LTN:LTP of sunny slopes was higher than that of shady slopes.

\section{Soil Ecological Stoichiometric Characteristics}

\section{STC, STN, STP, and SAP Content}

Over the entire life cycle of the $P$. tabuliformis plantation, the average STC content was between 4.88 and 26.34 $\mathrm{g} \cdot \mathrm{kg}^{-1}$ in sunny slopes and in shady slopes it ranged between 4.09 and $32.42 \mathrm{~g} \mathrm{~kg}^{-1}$ (Fig. 4A), while the average STN content was between 0.31 and $1.91 \mathrm{~g}^{\mathrm{kg}} \mathrm{gg}^{-1}$ in sunny slopes and in shady slopes it was between 0.27 and $2.08 \mathrm{~g} \mathrm{~kg}^{-1}$ (Fig. 4B). The average STP content ranged from 0.36 to $1.08 \mathrm{~g} \cdot \mathrm{kg}^{-1}$ in sunny slopes and in shady slopes it was between 0.64 and $1.80 \mathrm{~g} \mathrm{~kg}^{-1}$ (Fig. 4C), and the average SAP content was 14.72 to $19.06 \mathrm{mg} \cdot \mathrm{kg}^{-1}$ in sunny slopes and between 13.97 and $18.20 \mathrm{mg} \cdot \mathrm{kg}^{-1}$ in shady slopes (Fig. 4D).

The contents of STC and STN were not significantly different under different site conditions, but the contents of STP and SAP were significantly different under different site conditions. The contents of STC and STN in different soil layers were as follows: $>0-20 \mathrm{~cm}>20-40 \mathrm{~cm}>60 \mathrm{~cm}$. Moreover, the topsoil content $(0-20 \mathrm{~cm})$ was significantly different from that of the other soil layers. However, the contents of STP and SAP in different soil layers were generally found to be greater in the following order of soil depth: $0-60 \mathrm{~cm}>20-40 \mathrm{~cm}>0-20$ $\mathrm{cm}$. There was no significant difference in STP content among the different soil layers, however, there was a significant difference in SAP content between the 40 and $60 \mathrm{~cm}$ soil layer and other soil layers. In the sunny slopes, the element contents did not change with forest age, but almost all reached the maximum value in the OMF. In shady slopes, the contents of STC and STN in different soil layers changed with forest age in the same way, both increased first and then decreased, and all reached the maximum value in NMF. The change rule of STP content in different soil layers was found to be the same as STC and STN, and it reached the maximum value in MAF. SAP content in different soil layers decreased first and then increased with the increase in forest age, and the maximum value was found in YF. The results showed that the contents of STC and STN decreased with increasing soil depth, while the contents of STP and SAP were opposite. In the sunny slope, the element contents almost all reached a maximum in the OMF. In the shady slopes, STC, STN, and STP first increased and then decreased with increasing forest age, whereas SAP content decreased first and then increased with increasing forest age.

\section{Stoichiometric Ratio of STC, STN, and STP}

Over the entire life cycle of the $P$. tabuliformis plantation, the average STC:STN was between 12.87 and 16.94 in sunny slopes and in the shady slopes it ranged from 13.97 to 18.20 (Fig. 5A). The average STC:STP was found to be between 12.97 and 51.93 in sunny slopes and in shady slopes it was between 4.37 and 34.26 (Fig. 5B), while the average STN:STP ranged from 0.87 to 3.31 in sunny slopes and 0.35 and 2.36 in shady slope (Fig. 5C). STC:STN showed no significant difference under different site conditions, while STC:STP and STN:STP were significantly different under different site conditions. On sunny slopes, STC:STN, STC:STP, and STN:STP 
showed a downward trend with increasing soil depth. STC:STP and STN:STP first increased and then decreased with increasing forest age. In shady slopes, STC:STN changed irregularly with soil depth, and both STC:STP and STN:STP showed a decreasing trend with increasing soil depth. STC:STN reached the maximum value in YF at depths of $20-40 \mathrm{~cm}$ and $40-60 \mathrm{~cm}$. STC:STP and STN:STP both reached their maximum values in MF in the $20-40 \mathrm{~cm}$ and $40-60 \mathrm{~cm}$ soil layers. The results show that, except for the ratio of STC:STN in the shady slopes, the ratio decreases with an increase in soil depth. Except for the topsoil, the change trend of STC:STP and STN:STP in shady slopes and sunny slopes was consistent with forest age.

\section{Correlation of leaf Ecological Stoichiometry and Biomass with Soil Ecological Stoichiometry}

As shown in Table 2, in the sunny slopes, in YF, STC:STN had a significant negative correlation with LTN and LTN:LTP, and a significant positive correlation with LTC:LTN. STN:STP was significantly and positively correlated with LTC. There was a significant positive correlation between LTN and LTP. LTC:LTN, LTC:LTP, and LTN:LTP were significantly negatively correlated. In MAF, there was a significant negative correlation between biomass and LTN, and LTP and LTC:LTP was significantly negatively correlated. In NMF, there was a significant negative correlation between biomass and LTC:LTP. In MF, STC was negatively correlated with LTP and positively correlated with LTC:LTP. STN and LTC:LTP showed a significant positive correlation. SAP was positively correlated with LTC. LTC and LTN:LTP showed a significant negative correlation. In the OMF, SAP had a significant positive correlation with LTC:LTN. There was a significant positive correlation between biomass and STN:STP. LTP and LTN:LTP showed a significant negative correlation.

In the shady slopes, there is a significant positive correlation between LTC and LTN in YF, and a significant negative correlation between LTC, LTN, and LTC. LTN and LTC:LTN were negatively correlated. LTP and LTC:LTP showed a significant negative correlation. In NMF, there was a significant positive correlation between biomass and LTC. STP and LTC:LTP showed a significant positive correlation. STC:STP and LTC:LTP were significantly negatively correlated. STN:STP and LTP showed significant positive correlations. In MF, STC:STN, and LTN:LTP showed a significant positive correlation, while STN:STP and LTN:LTP showed a significant negative correlation. The correlation between LTN and LTC LTN was significantly negative. In the OMF, there was a significant positive correlation between biomass and STC:STP, while there was a significant negative correlation between LTC and LTN, a significant positive correlation between LTC and LTN, a significant positive correlation between LTC and LTP, and a significant positive correlation between LTC:LTP and LTN:LTP. There were significant negative correlations between LTN and LTC:LTN, LTC:LTP, and LTN:LTP. LTC:LTN, and LTC:LTP, LTC:LTP, and LTN:LTP were significantly positively correlated, while LTN:LTP and LTP showed a significant negative correlation. The results showed that the correlations among the elements were different for different stand ages and site conditions.

\section{Discussion}

\section{Effects of Site and Forest Age on Leaf Biomass}

In this study, the leaf biomass of the sunny slopes was higher than that of the shady slopes and increased with increasing forest age. This result is consistent with the results of Huang Xiaonan (2020). P. tabuliformis is a coniferous evergreen tree of Pinaceae. The species is greatly affected by light and because light had a certain promotion effect on the increase in leaf biomass, the leaf biomass of sunny slopes was slightly higher than 
that of shady slopes. And with an increase in forest age, the total biomass, aboveground biomass, and underground biomass of the tree layer all showed an increase, and thus, the leaf biomass would also increase with the increase in forest age.

In this study, the leaf biomass of shady slopes first increased and then decreased with increasing forest age. This is consistent with the research results of Zhang Ping (Zhang 2019), at the later stage of tree growth, the biomass growth of each stand stage showed a decreasing trend, indicating that the growth of trees was gradually stable, especially at the aged stage. Some studies believe that the death of trees is one of the main reasons for the decrease in forest biomass in the old forest age stage (Xu et al. 2012). In addition, the light is not sufficient on the shady slopes, therefore the biomass of $P$. tabuliformis leaves may decrease after it enters the aging stage. These results are consistent with the first hypothesis of this study, that is, the biomass of leaves in $P$. tabuliformis plantations is related to forest age and site conditions, and the biomass of leaves in different growth stages will change with the different needs of plants.

\section{Effects of Site and Forest Age on C:N:P Stoichiometric Characteristics of Leaves and Soil}

Previous studies have shown that with an increase in forest age, the content of carbon and phosphorus in plant leaves decreases at first and then increases, and that the LTC:LTP ratio increases at first and then decreases (Peipei et al. 2016). However, in this study, with the increase in forest age, LTC, LTN, and LTP contents, as well as LTC:LTN, LTC:LTP, and LTN:LTP ratios, did not change significantly with forest age, which was similar to previous research results (Peipei et al. 2016, Bingyan et al. 2015, Ning et al. 2015). These results may be influenced by different factors such as sampling time, forest age, site conditions, and climate environment of the growing place. This study also found that on sunny slopes, leaf nitrogen content of $P$. tabuliformis plantations reached a maximum in NMF, which was due to the fact that the $P$. tabuliformis plantation with NMF was in the peak growth period and needed more rRNA to meet the protein synthesis, thus leading to an increase in leaf nitrogen content.

In shady slopes, leaf nitrogen content of the $P$. tabuliformis plantation reached the maximum value in MF, which may be due to a lack of light. In addition, this species was in the peak growth stage in the MF stage. The change in nitrogen content in P. tabuliformis needles between forest ages directly affected the difference between stand ages of LTC:LTN and LTC:LTP. The changes in carbon, nitrogen, and phosphorus contents of the needles of the five forest ages were not consistent, which might be because the absorption and demand of soil nutrients were different with the increase in the age of the forest. In addition, the supply of soil nutrients under the forest also changed with the change of time and the comprehensive influence of various factors (Jingyuan et al. 2011). The carbon content of the leaves on the sunny slopes was higher than that of the leaves on the shady slopes, which may be because the leaves on sunny slopes undergo photosynthesis and accumulate more nutrients than those on shady slopes. The results verified that the element content of $P$. tabuliformis plantation leaves in the first hypothesis was related to forest age and site conditions, and the element content of leaves in different growth stages would change with the different needs of plants. The leaf carbon content of $P$. tabuliformis was significantly higher than that of 492 other terrestrial plants $\left(464 \mathrm{~g} \cdot \mathrm{kg}^{-1}\right)$ studied by Elser et al. (2000), indicating that the leaf organic compound content of P. tabuliformis was higher.

The nitrogen content of leaves was significantly lower than the average nitrogen content of Chinese plants $\left(20.2 \mathrm{~g} \mathrm{~kg}^{-1}\right)$ and the average nitrogen content of global plants $\left(20.6 \mathrm{~g} \cdot \mathrm{kg}^{-1}\right)$. In contrast, the phosphorus content 
in leaves was slightly higher than the average phosphorus content in China $\left(1.46 \mathrm{~g}^{\cdot} \mathrm{kg}^{-1}\right)$ and the average phosphorus content of global plants $\left(1.99 \mathrm{~g}^{\cdot \mathrm{kg}^{-1}}\right)$. The results showed that there was a lack of nitrogen in $P$. tabuliformis. Some studies have shown that when LTN:LTP is $>16$, plant growth is restricted by phosphorus. When LTN:LTP was less than 14, plant growth is considered to be restricted by nitrogen and when LTN:LTP is between 14 and 16, plant growth is considered to be restricted by both (Koerselman et al. 1996). In this study, the leaf LTN:LTP of $P$. tabuliformis plantations was below 14, indicating that the growth of $P$. tabuliformis plantations was mainly restricted by nitrogen. In the management of plantations, especially in the young stage of $P$. tabuliformis plantations, nitrogen fertilizer should be reasonably applied to improve the soil nutrient supply. Based on the principle of LTN:LTP stoichiometry, the changes in the LTN:LTP ratio in different age communities were studied. It was found that the main nutrient elements limiting plant growth in different age groups are of great significance for forest management to improve productivity.

The results showed that on sunny slopes, there was no obvious change in element content with forest age, however, almost all of them reached the maximum value in OMF. The reason may be that woodland litter gradually increases with an increase in time, which is consistent with the research results of Zhao et al. (2012). In shady slopes, the contents of STC and STN in different soil layers changed with forest age in the same way, both increased first and then decreased, and all reached the maximum value in NMF. The change rule of STP content in different soil layers is the same as above, and it reaches the maximum value in MAF. SAP content in different soil layers decreased first and then increased with the increase in forest age, with the maximum value being measured in YF. It may be that in the late growth period, due to insufficient illumination, weakened photosynthesis, and reduced synthetic organic matter, the demand of plants for soil nutrients increased, so the nutrient content in the soil decreased. The contents of STC and STN decreased with increasing soil depth, while the contents of STP and SAP were opposite. The soil contents of STC and STN were the highest in the surface layer $(0-20 \mathrm{~cm})$, showing a "surface aggregation" phenomenon, which was consistent with previous research results (Fujing et al. 2011). In this study, soil phosphorus content was lower than the global average level (2.8 $\mathrm{g} \cdot \mathrm{kg}^{-1}$ ) (Shujie et al. 2007), which is consistent with the previous findings reporting that soil phosphorus content in China is generally lower than the global level (Jiajia et al. 2014). Soil phosphorus is made available from the differentiation of soil minerals and the activities of microorganism, and with an increase in time, the external environment changes, and the hydrothermal conditions also change, leading to a change in phosphorus content. However, the main source of available phosphorus in soil is rock and mineral weathering, which is a steady and lengthy process. Therefore, soil phosphorous did not significantly change due to soil depth. In this study, except for SAP, the average soil element content was generally higher in shady slopes than in sunny slopes. This may be because the growth of $P$. tabuliformis in sunny slopes is better than that in shady slopes, and the nutrient demand is higher. Therefore, the soil transports more nutrients to $P$. tabuliformis in sunny slopes, so the nutrient content in the soil is relatively low.

\section{C:N:P Stoichiometric Characteristics of Soil and Leaves}

In this study, based on the correlation between leaf biomass and leaf carbon, nitrogen and phosphorus, and soil carbon, nitrogen, and phosphorus, it can be concluded that the higher the leaf carbon content, the higher the leaf biomass in sunny slopes, and the higher the STC:STP ratio, the higher the leaf biomass. The results showed that leaf biomass was related to leaf carbon, nitrogen content, and the LTC:LTP ratio, and STC:STP and STN:STP. In other words, leaf biomass can be adjusted by adjusting the soil carbon, nitrogen, and phosphorus 
contents. When soil nitrogen is sufficient, the leaf biomass can be improved. The results confirmed the second hypothesis, that is, soil C:N:P stoichiometric characteristics have a certain influence on leaf biomass. The stoichiometric characteristics of nitrogen and phosphorous in plant leaves were not significantly correlated with biomass change. This result is consistent with the findings of Yan Bangguo (2015). In shady slopes and YFs, it may be that the plants are in the early stage of structure construction and growth, which requires a large amount of protein synthesis from nitrogen and is also the period of biomass accumulation. Therefore, there is a significant positive correlation between LTC and LTN. In the OMF, LTC and LTN were negatively correlated. This result is consistent with the results of Ningning (2017), which may be due to the contradictory allocation of leaf nutrients between structural construction and rapid plant growth.

Under different site conditions, according to the correlation between leaf carbon, nitrogen, and phosphorus content and soil carbon, nitrogen, and phosphorus content, it can be seen that soil carbon, nitrogen, and phosphorus contents are related to leaf carbon, nitrogen, and phosphorus content, that is, the leaf carbon, nitrogen, and phosphorus content can be adjusted by adjusting the soil carbon, nitrogen, and phosphorus content. This result confirmed the third hypothesis, namely, that soil C:N:P stoichiometric characteristics significantly affect leaf C:N:P stoichiometric characteristics in the long run.

\section{Conclusions}

The age and site conditions of $P$. tabuliformis plantations had significant effects on leaf biomass. Forest age had no significant effect on the contents of total carbon, total nitrogen, and total phosphorus in leaves and soil, but site conditions had a certain effect on them. The biomass, LTC, LTC:LTN, LTC:LTP, and LTN:LTP of $P$ tabuliformis on sunny slopes were all higher than those on shady slopes, while the nitrogen and phosphorus contents of leaves showed an opposite trend. The contents of STC and STN decreased with increasing soil depth, while the contents of STP and SAP were opposite. In addition to SAP, the average content of STC, STN, and STP in shady slopes was higher than that in sunny slopes, and the ratios showed the opposite. Except for STC:STN in the shady slopes, the other ratios showed a downward trend with increasing soil depth. Except for the topsoil, the change trend of STC:STP and STN:STP in shady slopes and sunny slopes was consistent with forest age. The results showed that the biomass of leaves was mainly limited by nitrogen, and there was a lack of nitrogen in the leaves. In the management of $P$. tabuliformis plantations in this temperate mountainous area, it is suggested to plant on sunny slopes, and especially during the young stage of $P$. tabuliformis plantations. In addition, it is suggested to apply a reasonable amount of nitrogen fertilizer to improve the soil nutrient supply and increase the biomass of leaves. These results can provide a reference for the management of $P$. tabuliformis plantations in the temperate mountainous area of China.

\section{Declarations}

Author Contributions: Conceptualization, L.W. and P.L., methodology, L.W. and X.J., software, L.W., validation, L.W., X.J., and P.L., formal analysis, L.W., investigation, L.W., X.J., and L.Y., resources, L.Y., data curation, L.W., writing-original draft preparation, L.W., writing-review and editing, P.L., visualization, P.L., supervision, Y.W., project administration, P.L., funding acquisition, P.L. All authors have read and agreed to the published version of the manuscript. 
Funding: This research was funded by the National Key R\&D Program of China (2017YFD060050102).

\section{Acknowledgements}

We are particularly grateful to the following lab members for their help: Z.J., B.Q., and M.L.

\section{Ethics approval and consent to participate}

Not applicable.

\section{Consent for publication}

Not applicable.

\section{Competing interests}

The authors declare no competing interests.

\section{References}

1. Bing, W., Fengwei, Y., Hao, G. (2008) Code for Assessing Forest Ecosystem Services (LY/T1721-2008). Issued by State Forestry Administration.

2. Lin, Y (2020) Study on the Ecological Stoichiometric Characteristics of Larch Forest in Greater Hinggan Mountains, Inner Mongolia, Inner Mongolia Agricultural University.

3. Bowen, D., Yaoyao, X., Yifei, C., Shuo, Z., Dexiang, Z., Xiaoli, L., Renzhong, L., Shaofei, J. (2020)Analysis of Leaf Nitrogen, Phos-phorus and Potassium in Chinese Coniferous Forest. J. For. Res 33, 81-87.

4. Zhang, L.X., Bai, Y.F., Han, X.G (2004) Differential Responses of N:P Stoichiometry of Leymus chinensis and Carex Korshinskyito N Additions in a Steppe Ecosystem in Nei Mongol. Acta Bot. Sin 46, 259-270.

5. Wassen, M.J., Olde Venterink, H.G.M., De Swart, E.O.A.M (1995) Nutrient Concentrations in Mire Vegetation as a Measure of Nutrient Limitation in Mire Ecosystems. J. Veg. Sci 6, 5-16. DOI:10.2307/3236250.

6. Jingming, Y., Shihang, Z., Man, W., Wei, H., Shen, Q., Dong, Q., Ye, T (2021) Seasonal Dynamics of NPK Stoichiometry in the Branches and Leaves of an Endangered Plant Pinus chinensis in the Dabie Mountains. Chin. Bull. Bot. Research 41(03):395-407.

7. Yang, T., Zhong, Q.L., Li, B.Y., Cheng, D.L., Xu, C.B., Yu, H., Zou, Y.X (2020) Stoichiometric Characteristics and Allometric Rela-tionship of Carbon, Nitrogen and Phosphorus between Leaves and Fine Roots of Three Functional Forest Seedlings. Chin. J. Appl. Ecol 31, 4051-4057.

8. Junhua, R., Xingzhao, L., Guowei, C (2010) Soil Biol. Biochem. J. Plant Ecol 34(1): 64-71.

9. Huang, X.N (2020) Response and Simulation of Biomass Contrast Conditions and Stand Structure of Larix Principis-Rupprechtii Plantation in Liupanshan Mountain. Beijing Forestry University.

10. Wang, S.Q., Yu, G.R (2008) Ecological Stoichiometry Characteristics of Ecosystem Carbon, Nitrogen and Phosphorus Elements. Acta Bot. Sin 28, 3937-3947.

11. Wu, T.G., Wu, M., Liu, L., Xiao, J.H (2010) Seasonal Variations of Leaf Nitrogen and Phosphorus Stoichiometry of Three Herbaceous Species in Hangzhou Bay Coastal Wetlands, China. Chin. J. Plant Ecol 
$34,23-28$.

12. Zou, W.T., Zeng, W.S., Zhang, L.J., Zeng, M (2015) Modeling Crown Biomass for Four Pine Species in China. Forests 6, 433-449. DOI:10.3390/f6020433.

13. Mensah, S., Veldtman, R., du Toit, B., Glèlè Kakaï, R.G., Seifert, T (2016) Aboveground Biomass and Carbon in a South African Mistbelt Forest and the Relationships with Tree Species Diversity and Forest Structures. Forests 7, 79. DOI:10.3390/f7040079.

14. Yang, B., Xue, W., Yu, S., Zhou, J., Zhang, W (2019) Effects of Stand Age on Biomass Allocation and Allometry of Quercus Acutissima in the Central Loess Plateau of China. Forests 10, 1. DOI:10.3390/f10010041.

15. Wang, F.M., Xu, X., Zou, B., Guo, Z.H., Li, Z.A., Zhu, W.X (2013) Biomass Accumulation and Carbon Sequestration in Four Different Aged Casuarina equisetifolia Coastal Shelterbelt Plantations in South China. PLOS ONE 8, e77449. DOI:10.1371/journal.pone.0077449.

16. Lie, G.W., Xue, L (2016) Biomass Allocation Patterns in Forests Growing Different Climatic Zones of China. Trees 30, 639-646. DOI:10.1007/s00468-015-1306-0.

17. Güsewell, S., Gessner, M.O (2009) N:P Ratios Influence Litter Decomposition and Colonization by Fungi and Bacteria in Microcosms. Funct. Ecol 23, 211-219. DOI:10.1111/j.1365-2435.2008.01478.x.

18. Ting, L., Qiang, D., Zhiyou, Y., Feng, J (2015) The Change of Herb Biomass and Its Nitrogen and Phosphorus Stoichiometry Characteristics under the Latitude Gradient of the Loess Plateau. J. Plant Nutr. Fert 21, 743-751.

19. Xingzhao, L., Guoyi, Z., Deqiang, Z., Shizhong, L., Guowei, C., Junhua, Y (2010) The Stoichiometry of N and $P$ in Plants and Soils at Different Succession Stages of Southern Subtropical Forests. Chin. J. Plant Ecol $34,64-71$.

20. Elser, J.J., Dobberfuhl, D.R., Mackay, N.A., Schampel, J.H (1996) Organism Size, Life History, and N:P Stoichiometry. BioScience 46, 674-684. DOI:10.2307/1312897.

21. Elser, J.J., Fagan, W.F., Denno, R.F., Dobberfuhl, D.R., Folarin, A., Huberty, A., Interlandi, S., Kilham, S.S., McCauley, E., Schulz, K.L (2000) Nutritional Constraints in Terrestrial and Freshwater Food Webs. Nature 408, 578-580. DOI:10.1038/35046058.

22. Tessier, J.T., Raynal, D.J (2003) Use of Nitrogen to Phosphorus Ratios in Plant Tissue as an Indicator of Nutrient Limitation and Nitrogen Saturation. J. Appl. Ecol 40, 523-534. DOI:10.1046/j.13652664.2003.00820.x.

23. Giisewell, S., Giisewell, S.N (2004) N: P Ratios in Terrestrial Plants: Variation and Functional Significance. New Phytol 164, 243-266. DOI:10.1111/j.1469-8137.2004.01192.x.

24. Elser, J.J., Sterner, R.W., Gorokhova, Es (2010) Biological Stoichiometry from Genes to Ecosystems. Ecol. Lett 3, 540-550.

25. Sistla, S.A., Schimel, J.P (2012) Stoichiometric Flexibility as a Regulator of Carbon and Nutrient Cycling in Terrestrial Ecosystems under Change. New Phytol 196, 68-78. DOI:10.1111/j.1469-8137.2012.04234.x.

26. Usuda, H (1995) Phosphate Deficiency in Maize. V. Mobilization of Nitrogen and Phosphorus within Shoots of Young Plants and Its Relationship to Senescence. Plant Cell Physiol 36, 1041-1049.

DOI:10.1093/oxfordjournals.pcp.a078846. 
27. Kerkhoff, A.J., Enquist, B.J (2006) Ecosystem Allometry: the Scaling of Nutrient Stocks and Primary Productivity across Plant Communities. Ecol. Lett 9, 419-427. DOI:10.1111/j.1461-0248.2006.00888.x.

28. Shujie, R., Guirui, Y., Bo, T (2007) Studies on the Chemical Characteristics of Nitrogen and Phosphorus in Leaves of 654 Plants in the north-south Transboundary of Eastern China. J. Environ. Sci 28, 2665-2673.

29. Fan, D., Peiyong, L., Dehui, Z (2011) Soil, N. P Concentration and Leaf N,P Stoichiometry of Three Plants in the Songnen Plain. Chin. J. Ecol 30, 77-81.

30. Andrews, M., Raven, J.A., Lea, P.J., Sprent, J.I (2016) A Role for Shoot Protein in Shoot-Root Dry Matter Allocation in Higher Plants. Ann. Bot 97, 3-10. DOI:10.1093/aob/mcj009.

31. Fan, Z.Q., Wang, Z.Q., Wu, C., Sun, H.L., Xu, W.J., Huo, C.F (2008) Nitrogen and Biomass Partitioning Pattern in Root and Leaf of Fraxinus mandshurica Seedlings. Chin. Agric. Sci. Bull 24, 45-51.

32. Yaonian, X., Mingxi, J (2015) Research Progress in Forest Carbon Pool Characteristics and Driving Factors Analysis. Acta Bot. Sin 35, 926-933.

33. Zhang, P (2019) Biomass of Robinia pseudoacacia Plantation and Its Interannual Variation of N and P in the Zhifanggou Watershed, Ansai. Northwest A\&F University.

34. Xu, C.Y., Turnbull, M.H., Tissue, D.T., Lewis, J.D., Carson, R., Schuster, W.S.F., Whitehead, D., Walcroft, A.S., Li, J., Griffin, K.L (2012) Age-Related Decline of Stand Biomass Accumulation Is Primarily Due to Mortality and Not to Reduction in NPP Associated with Individual Tree Physiology, Tree Growth or Stand Structure in a Quercus-Dominated Forest. J. Ecol 100, 428-440. DOI:10.1111/j.1365-2745.2011.01933.x.

35. Peipei, J., Yang, C., Yunming, C., Fang, W (2016) Stoichiometric Characteristics of C, N and Pin Plants, Litter and Soil in Pinus Tabulaeformis Plantations of Different Ages. Acta Bot. Sin 36, 6188-6197.

36. Bingyan, L., Yunming, C., Yang, C., Xu, W(2015) Carbon and Nitrogen Storage and Distribution Pattern of Pinus Tabulaeformis Plantation Ecosystem in the Eastern Part of the Southern Slope of Qinling Mountains. Chin. J. Appl. Ecol 26, 643-652.

37. Ning, W., Youli, Z., Baitian, W., Ruijun, W (2015) Stoichiometric Characteristics of Carbon, Nitrogen and Phosphorus in Pinus Tabulaeformis Forest Ecosystem in Shanxi Province. Res. Soil Water Conserv 22, 7279.

38. Jingyuan, W., Shaoqiang, W., Renlan, L., Junhua, Y., Liqing, S., Shijie, H.C (2011) N:P Stoichiometry of the Dominant Plants of Four Forest Types in China. Chin. J. Plant Ecol 35, 587-595.

39. Koerselman, W., Meuleman, A.F.M (1996) The Vegetation N:P Ratio: a New Tool to Detect the Nature of Nutrient Limitation. J. Appl. Ecol 33, 1441-1450. DOI:10.2307/2404783区

40. Zhao, F.Z., Han, X.H., Yang, J.H.M., Tong, X.G., Kang Le, D.U.J (2012) The Variation Characteristics of Soil Organic Carbon and Nitrogen Density in Different Returning Farmland to Forestland in Loess Hilly Region. J. Soil Water Conserv. Research 19, 43-47, 51-52.

41. Fujing, P., Wei, Z., Kelin, W., Xunyang, H., Shichu, L., Guofu, W (2011) N:P Ecological Stoichiometry of Vegetation Litter in Typical Karst Peak-Clump Depression. Acta Bot. Sin 31, 335-343.

42. Jiajia, Y., Xiangru, Z., Lusha, M., Yanan, C., Tinghui, D., Shaoshan A (2014) Ecological Stoichiometric Relationship among Different Components of Robinia pseudoacacia Forest on Loess Plateau. Acta Pedol. Sin 51, 133-142.

43. Bang-Guo, Y., Gang-Cai, L., Bo, F., Guang-Xiong, H., Liang-Tao, S., Ji-Chao, L., JI Zhong-Hua (2015) A Relationships between Plant Stoichiometry and Biomass in an Arid-Hot Valley, Southwest China Chinese 
Journal of Plant Ecology 39, 807-815. DOI:10.17521/cjpe.2015.0077.

44. Ningning, D (2017) Influence of C, N, P Stoichiometric Characteristics of Typical Forests in Qinling Mountains on Community Biomass. Northwest Sci-Tech University of Agriculture and Forestry.

\section{Tables}

Table 1. Basic information of sample plots and sample trees 


\begin{tabular}{|c|c|c|c|c|c|c|c|c|c|c|c|}
\hline \multirow[t]{2}{*}{$\begin{array}{l}\text { Age } \\
\text { class }\end{array}$} & \multicolumn{2}{|c|}{ Sample plot } & \multicolumn{2}{|c|}{ Sample tree number } & \multicolumn{2}{|c|}{$\begin{array}{l}\text { Age } \\
\text { (a) }\end{array}$} & \multicolumn{2}{|l|}{$\begin{array}{l}\mathrm{DBH} \\
(\mathrm{cm})\end{array}$} & \multicolumn{2}{|c|}{$\begin{array}{l}\text { Tree height } \\
\text { (m) }\end{array}$} & \multirow{2}{*}{$\begin{array}{l}\text { Stand } \\
\text { density } \\
\text { Dtree } \cdot \mathrm{hm}^{-2} \square\end{array}$} \\
\hline & s1 & S2 & s1 & S2 & S1 & S2 & s1 & S2 & S1 & S2 & \\
\hline \multirow[t]{6}{*}{ YF } & \multirow[t]{2}{*}{$65 \#$} & \multirow[t]{2}{*}{$62 \#$} & 47 & 41 & 10 & 10 & 4.8 & 6.4 & 3.3 & 4.1 & 1600 \\
\hline & & & 48 & 42 & 10 & 10 & 7.3 & 8.6 & 3.8 & 4.8 & 1600 \\
\hline & \multirow[t]{2}{*}{$66 \#$} & \multirow[t]{2}{*}{$63 \#$} & 49 & 43 & 10 & 10 & 7.0 & 8.6 & 3.4 & 4.0 & 1600 \\
\hline & & & 50 & 44 & 10 & 10 & 5.7 & 6.1 & 3.8 & 4.5 & 1600 \\
\hline & \multirow[t]{2}{*}{ 67\# } & \multirow[t]{2}{*}{ 64\# } & 51 & 45 & 10 & 10 & 7.0 & 8.0 & 3.9 & 4.9 & 1600 \\
\hline & & & 52 & 46 & 10 & 10 & 6.1 & 9.2 & 4.8 & 4.6 & 1600 \\
\hline \multirow[t]{6}{*}{ MAF } & \multirow[t]{2}{*}{$36 \#$} & \multirow[t]{2}{*}{$60 \#$} & 23 & 37 & 28 & 28 & 17.3 & 17.7 & 11.0 & 12.7 & 1300 \\
\hline & & & 24 & 38 & 28 & 28 & 17.6 & 16.9 & 11.5 & 10.8 & 1300 \\
\hline & \multirow[t]{2}{*}{$37 \#$} & \multirow[t]{2}{*}{$61 \#$} & 25 & 39 & 27 & 28 & 17.9 & 14.3 & 11.0 & 12.0 & 1233 \\
\hline & & & 26 & 40 & 28 & 28 & 18.3 & 17.2 & 10.0 & 14.6 & 1233 \\
\hline & \multirow[t]{2}{*}{$38 \#$} & \multirow[t]{2}{*}{$68 \#$} & 27 & 53 & 27 & 28 & 17.7 & 17.2 & 10.0 & 13.1 & 1233 \\
\hline & & & 28 & 54 & 28 & 28 & 19.3 & 16.3 & 10.5 & 14.2 & 1233 \\
\hline \multirow[t]{6}{*}{ NMF } & \multirow[t]{2}{*}{$40 \#$} & \multirow[t]{2}{*}{ 70\# } & 29 & 57 & 31 & 31 & 17.9 & 18.7 & 10.5 & 11.5 & 916 \\
\hline & & & 30 & 58 & 31 & 31 & 19.4 & 22.9 & 11.0 & 12.5 & 916 \\
\hline & \multirow[t]{2}{*}{ 7\# } & \multirow[t]{2}{*}{ 30\# } & 5 & 19 & 31 & 31 & 22.0 & 21.3 & 13.0 & 13.0 & 1167 \\
\hline & & & 6 & 20 & 31 & 31 & 20.1 & 19.9 & 13.5 & 14.0 & 1167 \\
\hline & \multirow[t]{2}{*}{ 8\# } & \multirow[t]{2}{*}{ 69\# } & 7 & 55 & 31 & 31 & 21.3 & 20.3 & 12.0 & 13.2 & 1167 \\
\hline & & & 8 & 56 & 31 & 31 & 20.9 & 21.4 & 13.5 & 12.8 & 1167 \\
\hline MF & $6 \#$ & 53\# & 3 & 35 & 53 & 53 & 19.1 & 21.0 & 12.0 & 13.0 & 983 \\
\hline & & & 4 & 36 & 53 & 53 & 22.8 & 22.2 & 14.0 & 13.5 & 983 \\
\hline & $21 \#$ & $51 \#$ & 17 & 33 & 52 & 52 & 23.5 & 18.6 & 13.0 & 13.0 & 750 \\
\hline & & & 18 & 34 & 49 & 49 & 22.1 & 19.2 & 16.0 & 12.5 & 750 \\
\hline & $50 \#$ & $14 \#$ & 31 & 11 & 46 & 46 & 18.7 & 28.8 & 10.5 & 12.5 & 966 \\
\hline & & & 32 & 12 & 48 & 48 & 17.9 & 30.9 & 10.0 & 14.0 & 966 \\
\hline $\mathrm{OMF}$ & $4 \#$ & $16 \#$ & 1 & 13 & 68 & 68 & 27.8 & 26.6 & 12.0 & 11.0 & 700 \\
\hline & & & 2 & 14 & 68 & 68 & 25.7 & 24.3 & 14.5 & 12.5 & 700 \\
\hline & $11 \#$ & 71\# & 9 & 59 & 69 & 69 & 27.0 & 25.4 & 13.0 & 14.5 & 433 \\
\hline & & & 10 & 60 & 69 & 69 & 28.3 & 25.7 & 13.0 & 14.0 & 433 \\
\hline
\end{tabular}




\begin{tabular}{|lllllllllll|}
\hline $32 \#$ & $17 \#$ & 21 & 15 & 68 & 68 & 29.4 & 30.1 & 19.0 & 13.0 & 555 \\
\cline { 2 - 10 } & & 22 & 16 & 68 & 68 & 26.7 & 26.2 & 19.0 & 13.0 & 555 \\
\hline
\end{tabular}

${ }^{1}$ S1: Sunny slope, S2: Shady slope. YF: Young forest, MAF: Middle-aged forest, NMF: Near-mature forest, MF: Mature forest, OMF: Over-mature forest.

Table 2. Correlations of leaf and soil 


\begin{tabular}{|c|c|c|c|c|c|c|c|c|c|}
\hline Site & Age & variable & Biomass & LTC & LTN & LTP & LTC:LTN & LTC:LTP & LTN:LTP \\
\hline \multirow{14}{*}{$\begin{array}{l}\text { Sunny } \\
\text { slope }\end{array}$} & \multirow[t]{4}{*}{ YF } & STC:STN & -0.594 & -0.762 & $-.998 *$ & 0.982 & $.999 *$ & -0.995 & $-1.000 * *$ \\
\hline & & STN:STP & -0.13 & $.998 *$ & 0.764 & -0.575 & -0.696 & 0.644 & 0.73 \\
\hline & & LTN & 0.54 & 0.803 & 1 & -0.967 & -0.995 & 0.986 & $.999 *$ \\
\hline & & LTC:LTN & -0.621 & -0.74 & -0.995 & 0.988 & 1 & $-.998 *$ & $-.999 *$ \\
\hline & \multirow[t]{2}{*}{ MAF } & Biomass & 1 & -0.86 & $-.998 *$ & 0.653 & 0.982 & -0.677 & -0.814 \\
\hline & & LTP & 0.653 & -0.175 & -0.604 & 1 & 0.497 & $-1.000 *$ & -0.972 \\
\hline & NMF & Biomass & 1 & 0.966 & -0.556 & 0.994 & 0.463 & $-.997 *$ & -0.797 \\
\hline & \multirow[t]{4}{*}{ MF } & STC & 0.423 & -0.847 & 0.214 & $-.998 *$ & -0.096 & $.998 *$ & 0.869 \\
\hline & & STN & 0.298 & -0.768 & 0.081 & -0.981 & 0.038 & $.997 *$ & 0.795 \\
\hline & & SAP & -0.871 & $.998 *$ & -0.742 & 0.846 & 0.657 & -0.775 & -0.995 \\
\hline & & LTC & -0.84 & 1 & -0.7 & 0.877 & 0.61 & -0.812 & $-.999 *$ \\
\hline & \multirow[t]{3}{*}{ OMF } & SAP & -0.371 & -0.966 & -0.987 & -0.877 & $1.000 *$ & 0.917 & 0.873 \\
\hline & & STN:STP & $1.000 *$ & 0.579 & 0.494 & -0.146 & -0.374 & 0.053 & 0.153 \\
\hline & & LTP & -0.122 & 0.722 & 0.788 & 1 & -0.863 & -0.996 & $-1.000 * \star$ \\
\hline \multirow{14}{*}{$\begin{array}{l}\text { Shady } \\
\text { slope }\end{array}$} & \multirow[t]{3}{*}{ YF } & LTC & -0.567 & 1 & $.999 *$ & 0.986 & $-.999 *$ & -0.979 & 0.984 \\
\hline & & LTN & -0.606 & $.999 *$ & 1 & 0.977 & -1.000 ** & -0.968 & 0.992 \\
\hline & & LTP & -0.423 & 0.986 & 0.977 & 1 & -0.978 & $-.999 *$ & 0.941 \\
\hline & \multirow[t]{4}{*}{ NMF } & Biomass & 1 & $.999 *$ & -0.012 & -0.727 & 0.303 & 0.825 & 0.498 \\
\hline & & STP & 0.858 & 0.88 & 0.504 & -0.976 & -0.23 & $.998 *$ & 0.873 \\
\hline & & STC:STP & -0.831 & -0.856 & -0.546 & 0.986 & 0.278 & $-1.000 * *$ & -0.896 \\
\hline & & STN:STP & -0.675 & -0.708 & -0.73 & $.997 *$ & 0.499 & -0.974 & -0.976 \\
\hline & \multirow[t]{3}{*}{ MF } & STC:STN & 0.312 & -0.619 & 0.487 & -0.675 & -0.49 & 0.551 & $.999 *$ \\
\hline & & STN:STP & -0.333 & 0.637 & -0.506 & 0.658 & 0.51 & -0.532 & $-.998 *$ \\
\hline & & LTN & 0.982 & -0.987 & 1 & 0.316 & $-1.000 * *$ & -0.461 & 0.454 \\
\hline & \multirow[t]{4}{*}{ OMF } & STC:STP & $.997 *$ & -0.887 & 0.882 & 0.927 & -0.874 & -0.891 & -0.911 \\
\hline & & LTC & -0.85 & 1 & $-1.000 * *$ & -0.996 & $1.000 *$ & $1.000 * *$ & $.999 *$ \\
\hline & & LTN & 0.845 & $-1.000 * *$ & 1 & 0.995 & $-1.000^{*}$ & $-1.000 *$ & $-.998 *$ \\
\hline & & LTP & 0.896 & -0.996 & 0.995 & 1 & -0.993 & -0.996 & $-.999 *$ \\
\hline
\end{tabular}

${ }^{1}$ Notes: ${ }^{*} p<0.05, * * p<0.01$. Only the results with significant correlations are presented in the table. YF: Young forest, MAF: Middle-aged forest, NMF: Near-mature forest, MF: Mature forest, OMF: Over-mature forest. 
LTC: Leaf total carbon, LTN: Leaf total nitrogen, LTP: Leaf total phosphorus, STC: Soil total carbon, STN: Soil total nitrogen, STP: Soil total phosphorous, SAP: Soil available phosphorous.

\section{Figures}

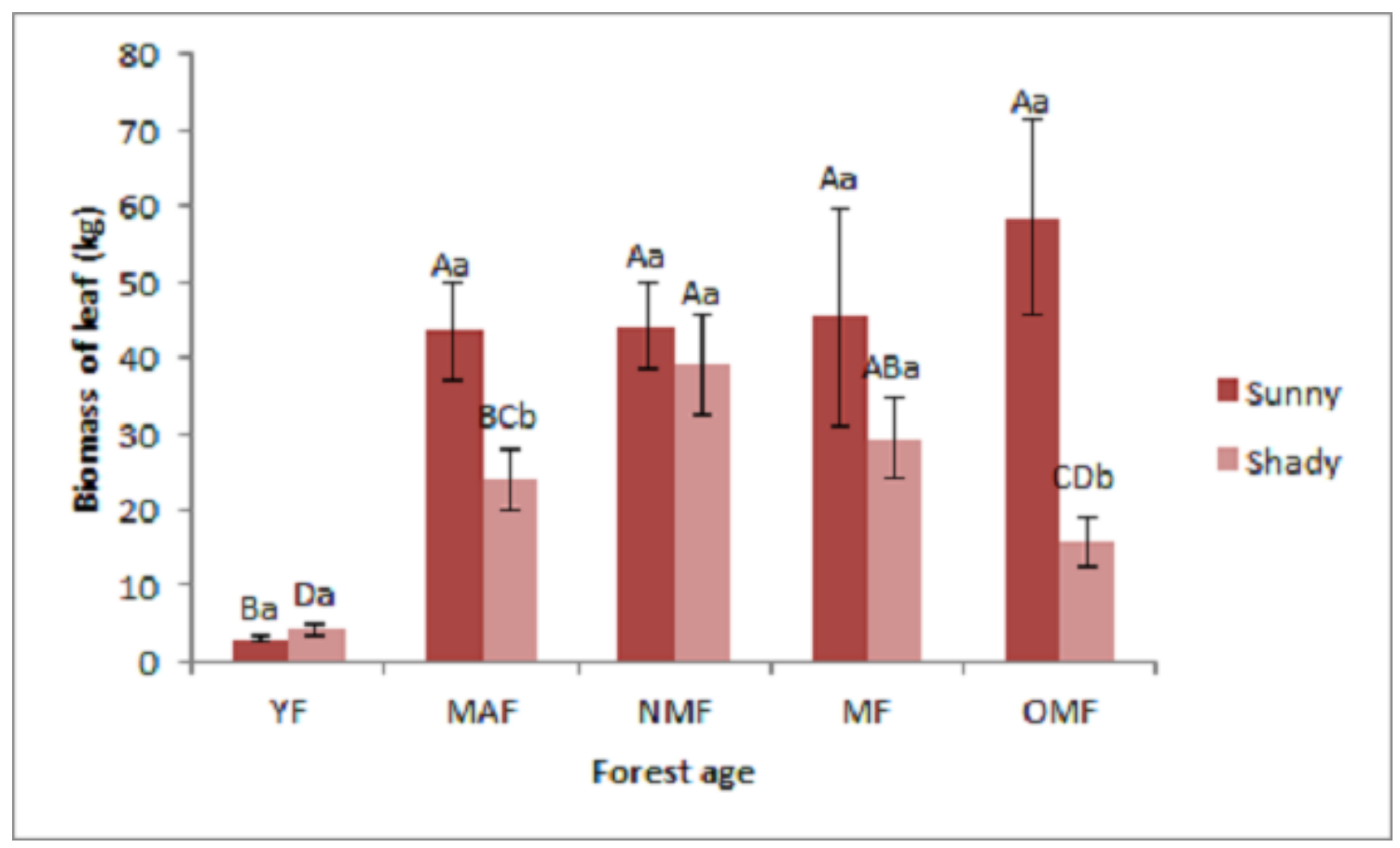

Figure 1

Biomass of leaf based on forest age and site. Different uppercase letters in the same site indicate significant differences between different forest ages, while different lowercase letters in the same forest age indicate significant differences between different sites $(p<0.05)$. YF: Young forest, MAF: Middle-aged forest, NMF: Nearmature forest, MF: Mature forest, OMF: Over-mature forest. Sunny: Sunny slope, Shady: Shady slope. 

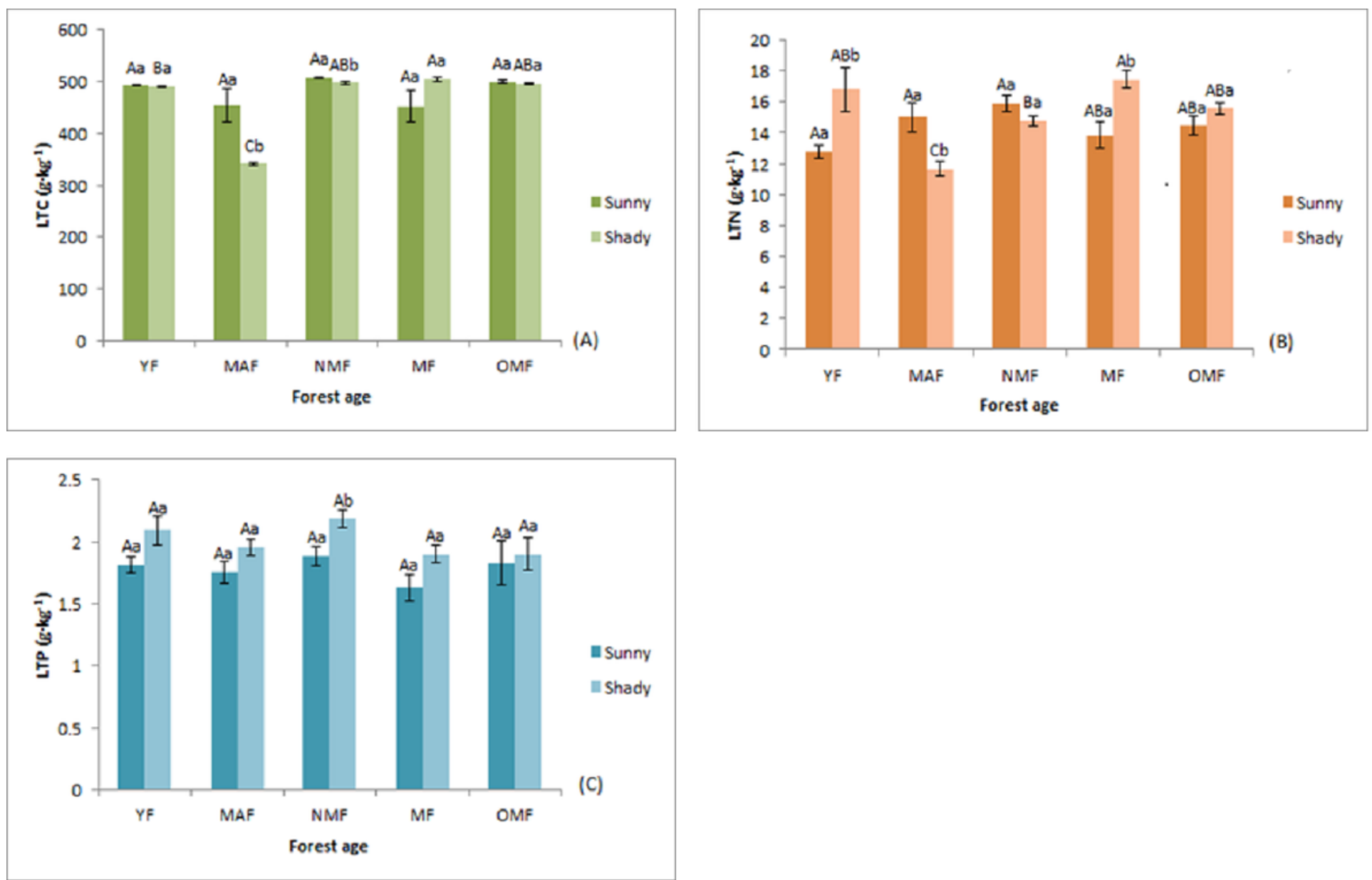

Figure 2

Carbon content of leaf (A), nitrogen content of leaf (B), and phosphorus content of leaf (C). Different uppercase letters in the same site indicate significant differences between different forest ages, while different lowercase letters in the same forest age indicate significant differences between different sites $(p<0.05)$. YF: Young forest, MAF: Middle-aged forest, NMF: Near-mature forest, MF: Mature forest, OMF: Over-mature forest. Sunny: Sunny slope, Shady: Shady slope. 

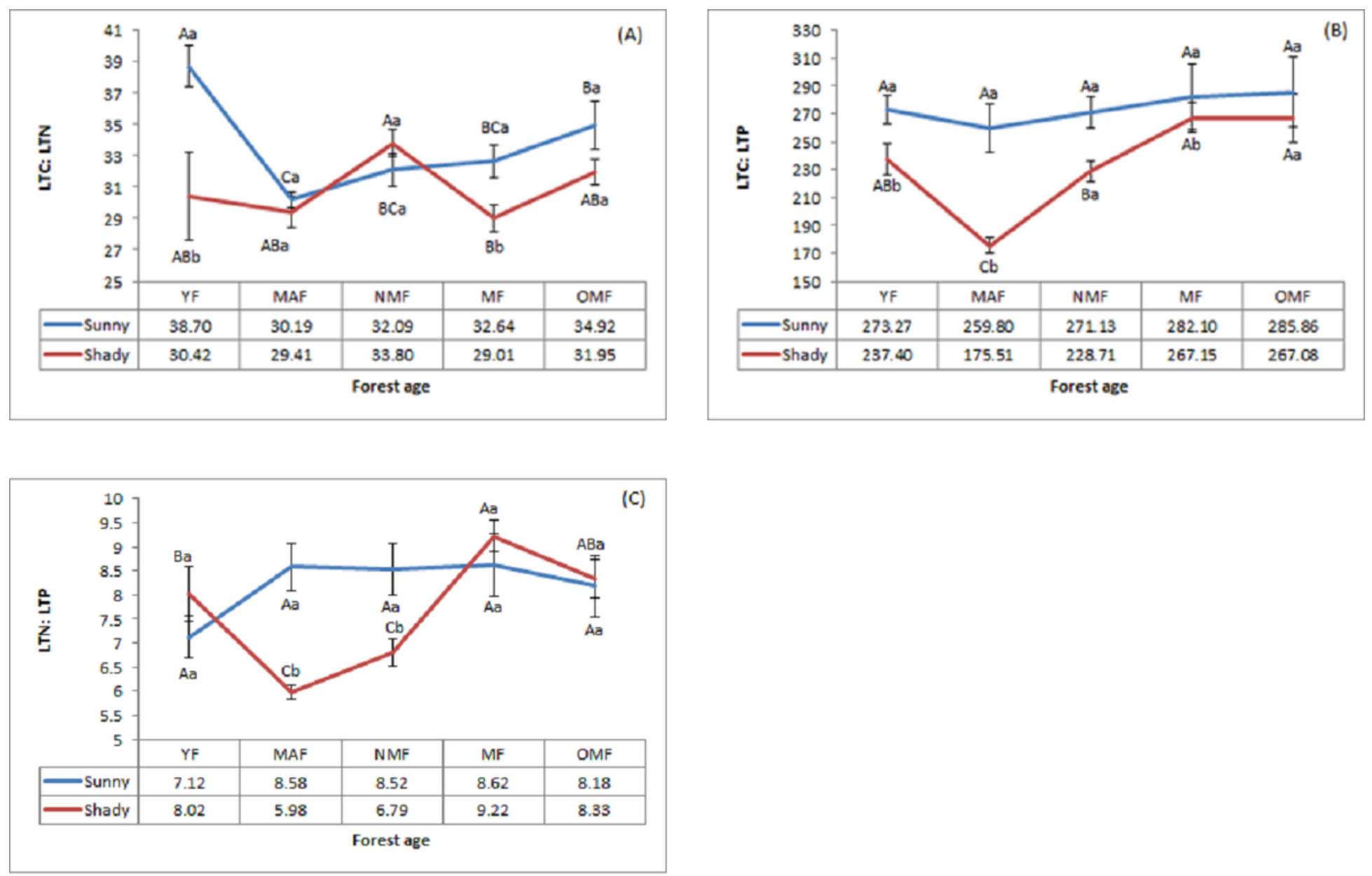

Figure 3

LTC:LTN of leaves (A), LTC:LTP of leaves (B), and LTN:LTP of leaves (C). Different uppercase letters in the same site indicate significant differences between different forest ages, while different lowercase letters in the same forest age indicate significant differences between different sites ( $p<0.05)$. YF: Young forest, MAF: Middleaged forest, NMF: Near-mature forest, MF: Mature forest, OMF: Over-mature forest. Sunny: Sunny slope, Shady: Shady slope. 

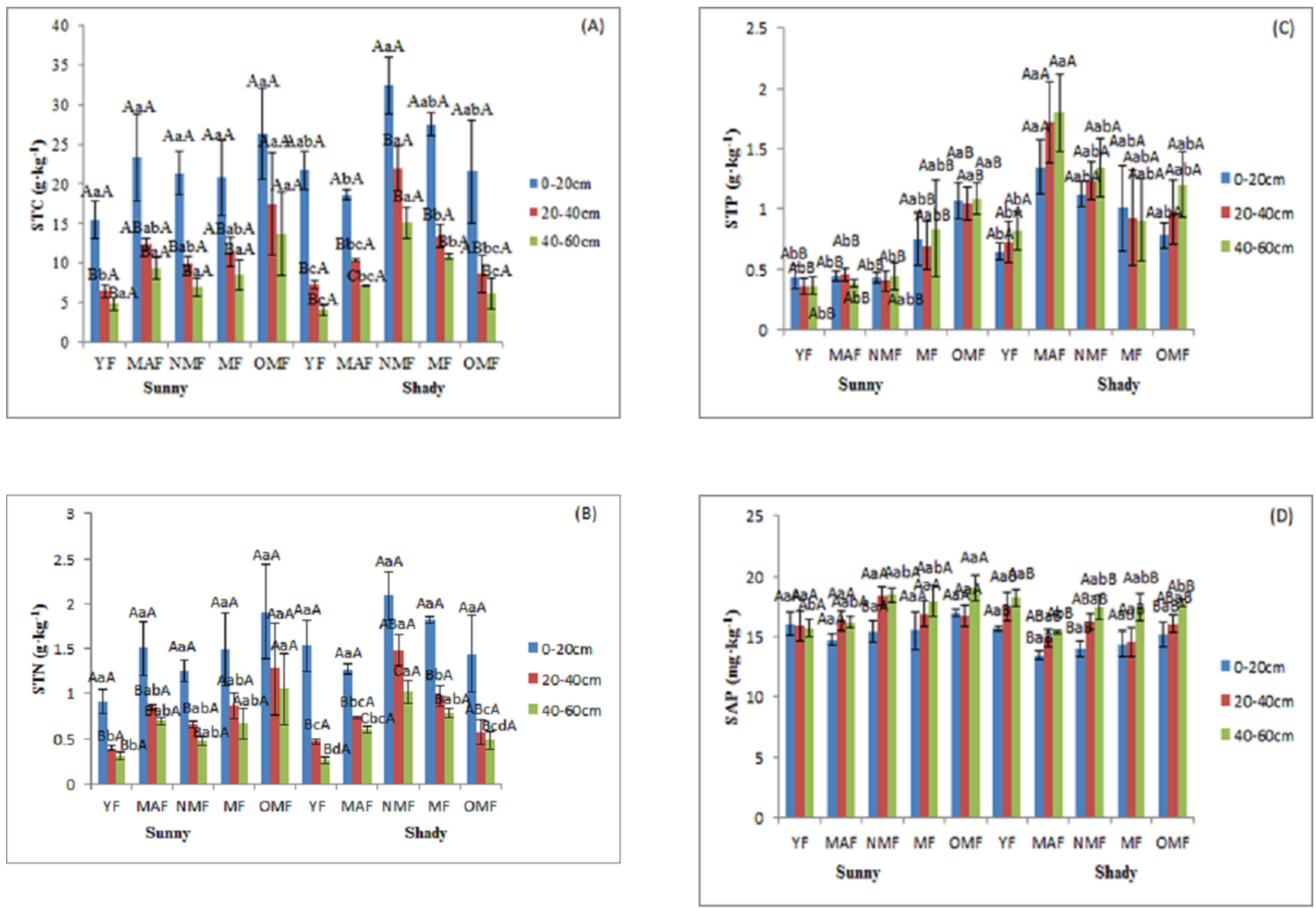

\section{Figure 4}

STC of soil (A), STN of soil (B), STP of soil (C), and SAP of soil (D). Different uppercase letters in the same forest age indicate significant differences between different soil layers, while different lowercase letters in the same soil layer indicate significant differences between different forest ages, and additional different uppercase letters indicate significant differences between different sites $(p<0.05)$. YF: Young forest, MAF: Middle-aged forest, NMF: Near-mature forest, MF: Mature forest, OMF: Over-mature forest. Sunny: Sunny slope, Shady: Shady slope. 

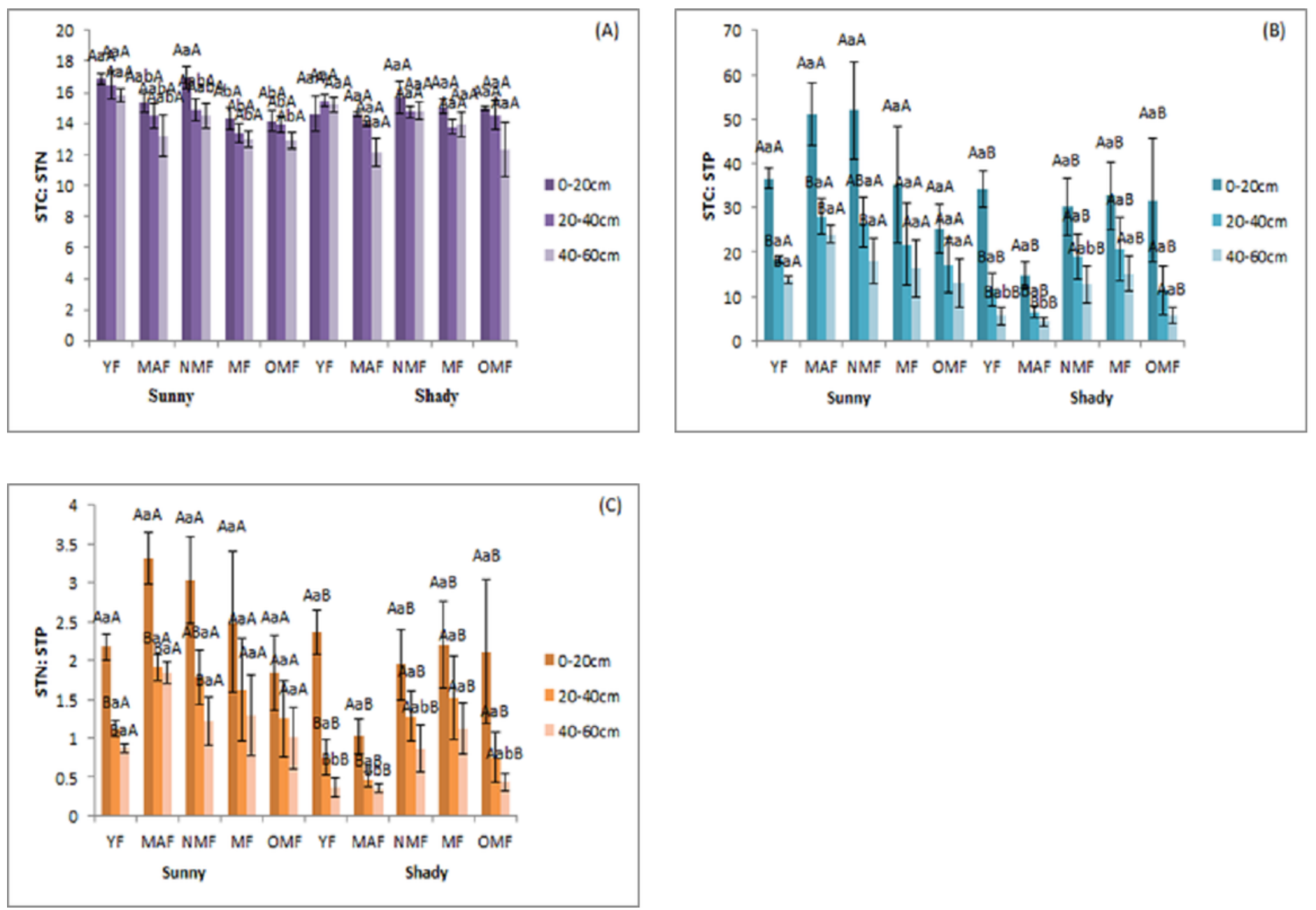

Figure 5

STC:STN (A), STC:STP (B), and STN:STP (C). Different uppercase letters in the same forest age indicate significant differences between different soil layers, while different lowercase letters in the same soil layer indicate significant differences between different forest ages, and additional different uppercase letters indicate significant differences between different sites $(p<0.05)$. YF: Young forest, MAF: Middle-aged forest, NMF: Nearmature forest, MF: Mature forest, OMF: Over-mature forest. Sunny: Sunny slope, Shady: Shady slope. 